\title{
Self-care practices and associated factors among adult hypertensive patients in Ayder Comprehensive Specialized Hospital, Tigray, Ethiopia, 2018
}

Gebrewahd Bezabh Gebremichael", Kalayou Kidanu Berhe, Birhane Gebrehiwot Beyene and Kiros Belay Gebrekidan

\begin{abstract}
Objectives: To assess self-care practices and associated factors among hypertensive patients in Ayder Comprehensive Specialized Hospital 2017/2018.

Result: Good self-care practice was found only among $20.3 \%$ of respondents. Adherence to not smoking, antihypertensive medication, alcohol abstinence, dietary management, physical exercise and weight management was found to be $99.1 \%, 74.10 \%, 67.20 \%, 63.10 \%, 49.4 \%$ and $40.6 \%$ respectively. Sex (AOR=2.254, 95\% Cl 1.092-4.653), age $(A O R=3.265,95 \% \mathrm{Cl} 1.030-10.355)$, educational status ( $A O R=4.205,95 \% \mathrm{Cl} 1.304-13.559)$, disease duration $(\mathrm{AOR}=3.124,95 \% \mathrm{Cl} 1.204-8.105), \mathrm{BP}$ status $(\mathrm{AOR}=2.728,95 \% \mathrm{Cl} 1.256-5.926)$ and knowledge $(\mathrm{AOR}=6.196,95 \% \mathrm{Cl}$ 2.906-13.214) showed significant statistical association with self-care practice.
\end{abstract}

Keywords: Self-care, Hypertension, Ethiopia

\section{Introduction}

Hypertension known as "the silent killer" is a major public health problem both in developed and developing countries [1]. It affects $22 \%$ of the world's population aged $\geq 18$ years [2] and 1.13 billion adults [3] and this number is expected to increase to 1.56 billion by 2025 [4]. Hypertension is the leading cause of death and disability accounting for 9.4 million annual deaths [5].

Hypertension related death and disability stem primarily from cardiovascular disease (CVD), renal failure and dementia [6]. For every $20 \mathrm{mmHg}$ increase in systolic blood pressure (BP) to $>115 \mathrm{mmHg}$ or $10 \mathrm{mmHg}$ increase in diastolic BP to $75 \mathrm{mmHg}$, the risk of cardiovascular and stroke events doubles [7]. Besides, hypertension costs about $10 \%$ of the global health expenditure [8].

\footnotetext{
*Correspondence: Neverimpossible12@yahoo.com
}

School of Nursing College of Health Science, Mekelle Univesity, Mekelle, Tigray, Ethiopia
Self-care practices have been proved as the determinants of hypertension prevention and control [9-11]. Major self-care practices for hypertension include medication adherence, maintenance of healthy body weight (body mass index (BMI) 18.5 to 24.9 , and waist circumference $102 \mathrm{~cm}$ for men and $88 \mathrm{~cm}$ for women), 30-60 min of moderate intensity exercise 4-7 days/week in addition to the routine activities, dietary approach to stop hypertension (DASH) and low salt diet, moderation of alcohol consumption (men $\leq 2$ and women $\leq 1$ alcoholic drink), cessation of smoking and stress management [10-13]. Hypertensive clients should also monitor their BP [14].

Despite the availability of anti-hypertensive drugs and optimal hypertension self-care practices are proved to decrease BP and all cause mortality rate and cardio-vascular morbidities $[15,16]$, hypertensive patients are suffering from unfavorable self-care practices. Many studies have shown that hypertensive patients have poor selfcare practices [17-21]. 
World health organization (WHO) develops Global Action Plan on; (1) 25\% reduction in non-communicable diseases (NCDs); (2) 10\% reduction in alcohol use; (3) $10 \%$ reduction in insufficient physical activity; (4) 30\% reduction in mean population salt intake; (5) $30 \%$ reduction in tobacco use; (6) 25\% reduction in prevalence of raised $\mathrm{BP} ;(7) 0 \%$ increase in obesity and diabetes; (8) at least $50 \%$ rate of eligible people receiving drug therapy to prevent heart attack and stroke to be achieved by 2025 using the year 2010 as the baseline [22].

To achieve this, cost-effective and research supported health care services drawing on the best available evidence are essential. Thus, the purpose of this study is to assess self-care practices and associated factors among hypertensive patients.

\section{Main text}

\section{Methods}

Study area and period: The study was conducted in Ayder Comprehensive Specialized Hospital (ACSH), Tigray, Ethiopia [23] from November 2017 to June 2018.

Study design and population: Hospital-based crosssectional study design was conducted. All adult hypertensive patients who had at least 6 months follow-ups were included as a source population. However unconscious and critical ill patients and pregnant mother were excluded.

Sample size determination: Sample size was determined using single population proportion formula considering: Prevalence (p) of lifestyle modification practice 0.273 [21] 95\% confidence interval and 5\% margin of error. Adding $5 \%$ none response rate the total sample size was 320 .

Sampling procedure and techniques: Sampling frame was created and participants were selected using simple random sampling technique.

\section{Study variables}

Independent variables: socio-demographic variables (age, sex, income, educational status, occupation and residence), health profile of patients (family history, BMI, BP monitoring, BP status, co-morbidity, disease duration and number and type of medication) and knowledge of hypertension and its management.

Dependent variable: self-care practice.

Data collection tool: data were collected using interviewer administered structured questionnaire. Self-care practice was assessed using Hypertension Self-Care Activity Level Effects (H-SCALE) which includes medication adherence, dietary management, smoking status, physical activity, weight management and alcohol intake. H-SCALE has provided detailed description of the scoring method of each component [24]. Hypertension evaluation of lifestyle and management (HELM) scale was used to assess respondents' knowledge [27].

\section{Operational definitions}

Good self-care practice: adherence to all the components of the H-SCALE.

Poor self-care practice: non-adherence to at least one component of the H-SCALE.

Good knowledge: scores of above mean value on HELM scale.

Poor knowledge: scores of below mean value on HELM scale.

Data quality assurance: training was given to data collectors and supervisors. Pretest was conducted in $5 \%$ of the samples in Axum comprehensive specialized hospital. Supervision was made, and data were checked at the spot.

Data processing and analysis: data were entered to EpiInfo and exported to SPSS for analysis. Descriptive statistics was done and binary logistic regression model was used to identify the associated factors. Significance was declared using adjusted odds ratios with $95 \%$ confidence interval $(\mathrm{CI})$ at $\mathrm{p}$-value $<0.05$.

\section{Result}

\section{Socio-demographic characteristics}

A total of 320 respondents (100\% response rate) were interviewed. Around $51.2 \%$ were females. The mean age of the respondents was $53.83 \pm 14.52$ years with a minimum age of 19 and a maximum age of 85 years. Majority of the respondents $(70.9 \%)$ were $<65$ years old. One hundred thirty-eight (43.1\%) of the respondents were not able to read and write (Table 1).

\section{Health profile related factors}

Ninety-seven (30.3\%) respondents had family history of hypertension. The mean duration of hypertension was $3.50 \pm 3.07$ with a range of $0.5-20$ years. Majority of respondents (67.2\%) had normal BMI and 50.3\% of respondents had medically confirmed co-morbidity. Most of the respondents (76.2\%) had $\geq 140 / 90 \mathrm{mmHg}$ average BP of three consecutive follow-ups. Ninety-six respondents (30\%) had ever missed follow-ups. Majority of respondents $(71.2 \%)$ was taking $\leq 2$ types of antihypertensive medications (Table 2).

\section{Information and knowledge}

Most of the respondents (91.9\%) got information about hypertension and its management. The mean score of knowledge was 4.3 . Nearly $45.6 \%$ of participants had good knowledge and $33.56 \%$ of them had good self-care practice. However, only $9.1 \%$ of participants with poor knowledge had good self-care practice. 
Table 1 Sociodemographic characteristics of hypertensive patients at ACSH, Mekelle, Tigray, Ethiopia, 2018 ( $n=320)$

\begin{tabular}{|c|c|c|c|c|}
\hline Variables & Category & $\begin{array}{l}\text { Good practice } \\
\text { N (\%) }\end{array}$ & $\begin{array}{l}\text { Poor practice } \\
\mathrm{N}(\%)\end{array}$ & $\begin{array}{l}\text { Total } \\
\text { N (\%) }\end{array}$ \\
\hline \multirow[t]{2}{*}{ Sex } & Male & $18(5.6)$ & $138(43.1)$ & $156(48.8)$ \\
\hline & Female & $47(14.7)$ & $117(37.2)$ & $164(51.2)$ \\
\hline \multirow[t]{2}{*}{ Age } & $<65$ & $60(18.8)$ & $166(51.9)$ & $226(70.6)$ \\
\hline & $\geq 65$ & $5(1.6)$ & $89(27.8)$ & $94(29.4)$ \\
\hline \multirow[t]{5}{*}{ Educational status } & Can't read an d write & $12(3.8)$ & $125(39.1)$ & $137(42.8)$ \\
\hline & Can read and write & $8(2.5)$ & $46(14.4)$ & 54 (16.9) \\
\hline & Primary & $3(0.9)$ & $19(5.9)$ & $22(6.9)$ \\
\hline & Secondary & $6(1.9)$ & $12(3.8)$ & $18(5.6)$ \\
\hline & Collage and above & $36(11.2)$ & $53(16.6)$ & $89(27.8)$ \\
\hline \multirow[t]{7}{*}{ Occupation } & Farmer & $9(2.8)$ & $46(14.4)$ & $55(17.2)$ \\
\hline & Civil servant & $16(5)$ & $48(15)$ & $64(20)$ \\
\hline & House wife & $8(2.5)$ & $23(7.2)$ & $31(9.7)$ \\
\hline & Self employed & $21(6.6)$ & $65(20.3)$ & $86(26.9)$ \\
\hline & Pensioned & $1(0.3)$ & $3(0.9)$ & $4(1.2)$ \\
\hline & Unemployed & $7(2.2)$ & $63(19.7)$ & $70(21.9)$ \\
\hline & Others & $3(0.9)$ & $7(2.2)$ & $10(3.1)$ \\
\hline \multirow[t]{3}{*}{ Income } & $<500$ & $2(0.6)$ & $20(6.2)$ & $22(6.9)$ \\
\hline & $500-1000$ & $16(5)$ & $105(32.8)$ & $121(37.8)$ \\
\hline & $>1000$ & $45(14.1)$ & $132(41.2)$ & $177(55.3)$ \\
\hline \multirow[t]{2}{*}{ Residence } & Urban & $54(16.9)$ & $178(55.6)$ & $232(72.5)$ \\
\hline & Rural & $9(2.8)$ & 79 (24.7) & 88 (27.5) \\
\hline
\end{tabular}

Table 2 Distribution of health profile of hypertensive patients at ACSH, Mekelle, Tigray, Ethiopia $2018(n=320)$

\begin{tabular}{|c|c|c|c|c|}
\hline Variables & Category & $\begin{array}{l}\text { Good practice } \\
\text { N (\%) }\end{array}$ & $\begin{array}{l}\text { Poor practice } \\
\mathrm{N}(\%)\end{array}$ & $\begin{array}{l}\text { Total } \\
\mathrm{N}(\%)\end{array}$ \\
\hline \multirow[t]{2}{*}{ Family history } & Yes & $25(7.8)$ & $72(22.5)$ & $97(30.3)$ \\
\hline & No & $38(11.9)$ & $185(57.8)$ & $223(69.7)$ \\
\hline \multirow[t]{3}{*}{ Disease duration (years) } & $<2$ & $11(3.4)$ & $63(19.7)$ & $74(23.1)$ \\
\hline & $2-4$ & $21(6.6)$ & $113(35.3)$ & $134(41.9)$ \\
\hline & $\geq 4$ & $31(9.7)$ & $81(25.3)$ & $112(35)$ \\
\hline \multirow[t]{4}{*}{ BMl } & Under-weight & $3(0.9)$ & $13(4.1)$ & $16(5)$ \\
\hline & Normal & $4(12.8)$ & $174(54.4)$ & $215(67.2)$ \\
\hline & Over-weight & $17(5.3)$ & $65(20.3)$ & $82(25.6)$ \\
\hline & Obesity & $2(0.6)$ & $5(1.6)$ & $7(2.2)$ \\
\hline \multirow[t]{2}{*}{ Co-morbidity } & Yes & $34(10.6)$ & $127(39.7)$ & $162(50.3)$ \\
\hline & No & $29(9.1)$ & $130(40.6)$ & $159(49.7)$ \\
\hline \multirow[t]{2}{*}{ BP status } & Controlled & $95(7.8)$ & $51(15.9)$ & $76(23.8)$ \\
\hline & Uncontrolled & $38(11.9)$ & $206(64.4)$ & $244(76.2)$ \\
\hline \multirow[t]{2}{*}{ Regular BP check (twice a month) } & Yes & $34(10.6)$ & $103(32.2)$ & $137(42.8)$ \\
\hline & No & $31(9.7)$ & $152(47.5)$ & $183(57.2)$ \\
\hline \multirow[t]{2}{*}{ Miss follow up } & Yes & $11(3.4)$ & $85(26.6)$ & $96(30)$ \\
\hline & No & $52(16.2)$ & $172(53.8)$ & $224(70)$ \\
\hline \multirow[t]{2}{*}{ Number of type of medication } & $\leq 2$ & $49(15.3)$ & $179(55.9)$ & $228(71.2)$ \\
\hline & $\geq 3$ & $14(4.4)$ & $78(24.4)$ & $92(28.8)$ \\
\hline
\end{tabular}




\section{Self care practice}

Good self-care practice was found only among 20.3\% [95\% CI 15.9-24.7] of respondents. Around 99.1\% of respondents were non-smokers. Nearly three-fourth (74.10\%) of participants were adherent to anti-hypertensive medication. More than two-third (67.20\%) of participants were non-drinkers. Adherence to dietary management, physical exercise and weight management were found to be $63.10 \%, 49.4 \%$ and $40.6 \%$ respectively.

\section{Factors associated with self-care practice}

Sex, age, educational status, monthly income, residency, family history, disease duration, BP status, BP check up, follow up miss, number and type of medication, information and knowledge were significant in the bivariate logistic regression. However, in the multivariable binary logistic regression analysis, only sex, age, educational status, disease duration, BP status and knowledge were independent predictors of self-care practices.

Females were found 2.254 times more likely to have good self-care practice than males $(\mathrm{AOR}=2.254,95 \% \mathrm{CI}$ $1.092-4.653, \mathrm{p}=0.028)$. Patients aged $<65$ years old were 3.265 times more likely to have good self-care practice than patients $\geq 65$ years old (AOR $=3.265$, 95\% CI 1.030 $10.355, \mathrm{p}=0.044)$. Having educational status of college and above was found to be 4.205 times more associated to good self-care practice than unable to read and write $[\mathrm{AOR}=4.205,95 \%$ CI 1.304-13.559, $\mathrm{p}=0.016$ ).

Respondents with $\geq 4$ years of disease duration were 3.124 times more likely to practice good self-care as compared to those with $<2$ years of disease duration $(\mathrm{AOR}=3.124,95 \%$ CI 1.204-8.105, p=0.019). Controlled BP was found 2.7 times more associated to good self-care practice than uncontrolled $\mathrm{BP}(\mathrm{AOR}=2.728$, 95\% CI 1.256-5.926, $\mathrm{p}=0.011)$. Good knowledge was found 6.196 times more positively associated to good self-care practice than poor knowledge $(A O R=6.196$, 95\% CI 2.906-13.214, p =0.000) (Table 3).

\section{Discussion}

Good self-care practice was found only among 20.3\% [95\% CI 15.9-24.7] of the respondents. This finding is consistent with the studies conducted in Addis Ababa (23\%) [20] and Nigeria (16.4\%) [19]. However, this finding is lower than the study conducted in south Ethiopia (27.3\%) [21] and India (37.1\%) [25]. This could be explained by socio-cultural variation that influences life style of individuals, sample size difference and variation in the components of self-care practice assessment tool.

Being female was 2.25 [AOR $=2.25,95 \%$ CI 1.09-4.65, $\mathrm{p}=0.028$ ] more likely associated with good self-care practice. This is in line with the study conducted in
Addis Ababa [20]. This consistency could be because of females are more adherent to the most components of the H-SCALE. It could also be due to socio-environmental and cultural reasons i.e. females may not smoke or use alcohol not essentially due to their hypertensive condition but could be attributed to societal culture.

Respondents $<65$ years old had 3.26 [AOR $=3.26$, CI $95,1.03-10.35, \mathrm{p}=0.044]$ more good self-care practice than $\geq 65$ years old respondents. This finding was in line with the study conducted in India which showed older age is associated with unfavorable self-care practice [25]. This was supported by the study conducted in South Ethiopia which showed patients aged $\geq 65$ years were less likely to have good lifestyle modification practice than patients with $<65$ years [21]. But this study finding is in contradict to the study finding conducted in Addis Ababa and Israel which showed younger age is less likely associated with self-care practice $[20,26]$. This might be due to the difference in participants' age categorization and sample size.

Respondents who had an educational status of college and above had 4.21 [AOR =4.21, 95\% CI 1.304-13.559, $\mathrm{p}=0.016]$ more good self-care practice than those who cannot read and write. This is in line with the study conducted in India [17]. Having good educational status helps individuals to have good knowledge and thus promotes respondents' good self-care practices.

Greater than 4 years of disease duration was 3.12 [AOR $=3.12,95 \%$ CI 1.20-8.10, $\mathrm{p}=0.019]$ more likely associated with good self-care practice than $<2$ years of disease duration. This is supported by the studies conducted Addis Ababa [20] and South Ethiopia [21] which showed that patients with longer disease duration had good life-style modification practice. This consistency could be due to the continued counseling' and health education on self-care practice.

Controlled BP was found 2.73 [AOR $=1.25 .95 \% \mathrm{CI}$ $5.92, \mathrm{p}=0.011]$ more likely associated with good self-care practice. This might be because of hypertension is essentially controlled and reduced by good self-care practices.

Good knowledge was 6.19 times more associated to good self care practice $[A O R=6.19,95 \%$ CI 2.9-13.2, $\mathrm{p}=0.000]$. This is also backed by the study conducted in Addis Ababa [20]. This similarity could be due to having good knowledge promote patients to give more emphasis on self-care practice.

\section{Limitations}

There may have been recall bias and social desirability bias since the self-care practices of the study participants were based on self-reports. There are no adequate similar studies on self-care practice and most literatures used 
Table 3 Bivariate and multivariable logistic regression analysis result for significant variables among hypertensive attending at ACSH, Mekelle, Tigray Region, Ethiopia $2018(n=320)$

\begin{tabular}{|c|c|c|c|c|c|c|}
\hline Variables & Category & $\begin{array}{l}\text { Good practice } \\
\text { N (\%) }\end{array}$ & $\begin{array}{l}\text { Poor practice } \\
\mathrm{N}(\%)\end{array}$ & COR & AOR & $p$-value \\
\hline \multirow[t]{2}{*}{ Sex } & Male & $18(5.6)$ & $138(43.1)$ & 1 & 1 & \\
\hline & Female & $47(14.7)$ & $117(36.6)$ & $3.08(1.696-5.592)$ & $2.254(1.092-4.653)^{* *}$ & 0.028 \\
\hline \multirow[t]{2}{*}{ Age } & $<65$ & $60(18.8)$ & $166(51.9)$ & $6.434(2.493-16.602)$ & $3.265(1.030-10.355)^{* *}$ & 0.044 \\
\hline & $\geq 65$ & $5(1.6)$ & $89(27.8)$ & 1 & 1 & \\
\hline \multirow[t]{5}{*}{ Educational status } & Can't read \$ write & $12(3.8)$ & $125(39.1)$ & 1 & 1 & \\
\hline & Can read \$ write & $8(2.5)$ & $46(14.4)$ & $1.812(0.696-4.714)$ & $1.228(0.353-4.278)$ & 0.747 \\
\hline & Primary & $3(0.9)$ & $19(5.9)$ & $1.645(0.425-6.370)$ & $1.174(0.211-6.538)$ & 0.854 \\
\hline & Secondary & $6(1.9)$ & $12(3.8)$ & $5.208(1.657-16.368)$ & $4.131(0.861-19.813)$ & 0.076 \\
\hline & Collage $\$$ above & $36(11.2)$ & $53(16.6)$ & $7.075(3.416-14.653)$ & $4.205(1.304-13.559)^{* *}$ & 0.016 \\
\hline \multirow[t]{3}{*}{ Income } & $<500$ & $2(0.6)$ & $20(6.2)$ & 1 & 1 & \\
\hline & $500-1000$ & $16(5)$ & $105(32.8)$ & $1.524(0.325-7.149)$ & $2.205(0.316-15.402)$ & 0.425 \\
\hline & $>1000$ & $45(14.1)$ & $132(41.2)$ & $3.615(0.814-16.063)$ & $2.646(0.375-18.666)$ & 0.329 \\
\hline \multirow[t]{2}{*}{ Residence } & Urban & $56(17.5)$ & $176(55)$ & $2.793(1.316-5.926)$ & $1.101(0.354-3.420)$ & 0.868 \\
\hline & Rural & $9(2.8)$ & $79(24.7)$ & 1 & 1 & \\
\hline \multirow[t]{2}{*}{ Family $\mathrm{Hx}$} & Yes & $25(7.8)$ & $72(22.5)$ & $1.728(0.980-3.045)$ & $1.346(0.632-2.865)$ & 0.441 \\
\hline & No & $38(11.9)$ & $185(57.8)$ & 1 & 1 & \\
\hline \multirow[t]{3}{*}{ Disease duration (years) } & $<2$ & $11(3.4)$ & $63(19.7)$ & 1 & 1 & \\
\hline & $2-4$ & $21(6.6)$ & $113(35.3)$ & $1.015(0.470-2.189)$ & $0.563(0.218-1.454)$ & 0.235 \\
\hline & $\geq 4$ & $31(9.7)$ & $81(25.3)$ & $1.977(0.940-4.161)$ & $3.124(1.204-8.105)^{* *}$ & 0.019 \\
\hline \multirow[t]{2}{*}{ BP status } & Controlled & $95(7.8)$ & $51(15.9)$ & $2.733(1.523-4.905)$ & $2.728(1.256-5.926)^{* *}$ & 0.011 \\
\hline & Uncontrolled & $38(11.9)$ & $206(64.4)$ & 1 & 1 & \\
\hline \multirow[t]{2}{*}{ BP check } & Yes & $34(10.6)$ & $103(32.2)$ & 1.619 (0.936-2.798) & $0.7(0.318-1.541)$ & 0.375 \\
\hline & No & $31(9.7)$ & $152(47.5)$ & 1 & 1 & \\
\hline \multirow[t]{2}{*}{ Miss follow up } & Yes & $11(3.4)$ & 85 (26.6) & 1 & 1 & \\
\hline & No & $52(16.2)$ & $172(53.8)$ & $2.455(1.221-4.936)$ & $1.508(0.628-3.618)$ & 0.358 \\
\hline \multirow[t]{2}{*}{ № $\$$ type medication } & $\leq 2$ & $49(15.3)$ & $179(55.9)$ & $1.605(0.839-3.071)$ & $1.203(0.511-2.836)$ & 0.672 \\
\hline & $\geq 3$ & $14(4.4)$ & $78(24.4)$ & 1 & 1 & \\
\hline \multirow[t]{2}{*}{ Information } & Yes & $63(19.7)$ & $231(72.2)$ & $3.273(0.753-14.222)$ & $2.880(0.488-16.990)$ & 0.243 \\
\hline & No & $2(0.6)$ & $24(7.5)$ & 1 & 1 & \\
\hline \multirow[t]{2}{*}{ Knowledge } & Good & $49(15.3)$ & $97(30.3)$ & $4.988(2.688-9.258)$ & $6.196(2.906-13.214)^{* *}$ & 0.000 \\
\hline & Poor & $16(5)$ & $156(49.4)$ & 1 & & \\
\hline
\end{tabular}

**AOR is significant at $p$-value $<0.05$

different statistical analysis. Thus, comparisons were difficult in self-care practices.

\section{Abbreviations \\ ACSH: Ayder Comprehensive Specialized Hospital; AOR: adjusted odds ratio; COR: crude odds ratio; BMI: body max index; BP: blood pressure; Cl: confidence interval; CVD: cardiovascular disease; DASH: Dietary Approaches to Stop Hypertension; HELM: hypertension evaluation of lifestyle and management; HRERC: Health Research Ethics Review Committee; H-SCALE: Hypertension Self-Care Activity Level Effect; NCD: non-communicable disease; SPSS: Statisti- cal Package for Social Sciences; WHO: World Health Organization.}

\section{Acknowledgements}

We would like to acknowledge Mekelle University for the priceless support in the accomplishment of this project. We are grateful to the data collectors for their cooperation in the data collection process. We would like also to give our heartfelt thanks to our study participants for their cooperation in provision of their information.

\section{Authors' contributions}

GBG: conception, design, acquisition, data collection, analysis and interpretation of data and drafting the manuscript. KKB critically reviewed the design, analysis, interpretation and the drafted manuscript. BGB participate in reviewing of the design, data collection, analysis, interpretation and the drafted manuscript. KBG also participate in reviewing of the design, data collection, analysis, interpretation and the drafted manuscript. All authors read and approved the final manuscript.

\section{Funding}

Financial support was obtained from Mekelle University.

Availability of data and materials

Raw data can be made available on request to the corresponding author. 


\section{Ethics approval and consent to participate}

Ethical approval was receipt from the Health Research Ethics Review Committee (HRERC) of Mekelle university college of health science (ERC 1293/2018). Written informed consent was also obtained from all participants.

\section{Consent for publication}

Not applicable.

\section{Competing interests}

The authors declare that they have no competing interests.

Received: 3 December 2018 Accepted: 20 July 2019

Published online: 06 August 2019

\section{References}

1. Bell K, Twiggs J, Olin BR. Hypertension: the silent killer: updated JNC-8 guideline recommendations. Alabama Pharmacy Association. 2015:1-8.

2. World Health Organization (WHO). Global status report on noncommunicable diseases 2014: attaining the nine global noncommunicable diseases targets; a shared responsibility. Geneva: World Health Organization; 2014. p. 2014.

3. Collaboration NRF. Worldwide trends in blood pressure from 1975 to 2015: a pooled analysis of 1479 population-based measurement studies with 19.1 million participants. Lancet. 2017;389(10064):37.

4. Kearney PM, Whelton M, Reynolds K, Muntner P, Whelton PK, He J. Global burden of hypertension: analysis of worldwide data. Lancet. 2005:365(9455):217-23.

5. Lim SS, Vos T, Flaxman AD, Danaei G, Shibuya K, Adair-Rohani H, et al. A comparative risk assessment of burden of disease and injury attributable to 67 risk factors and risk factor clusters in 21 regions, 1990-2010: a systematic analysis for the Global Burden of Disease Study 2010. Lancet. 2013;380(9859):2224-60.

6. Rapsomaniki E, Timmis A, George J, Pujades-Rodriguez M, Shah AD Denaxas $\mathrm{S}$, et al. Blood pressure and incidence of twelve cardiovascular diseases: lifetime risks, healthy life-years lost, and age-specific associations in 1.25 million people. Lancet. 2014;383(9932):1899-911.

7. Weber MA, Schiffrin EL, White WB, Mann S, Lindholm LH, Kenerson JG, et al. Clinical practice guidelines for the management of hypertension in the community. J Clin Hypertens. 2014;16(1):14-26.

8. Gaziano TA, Bitton A, Anand S, Weinstein MC. The global cost of nonoptimal blood pressure. J Hypertens. 2009;27(7):1472-7.

9. McManus RJ, Mant J, Bray EP, Holder R, Jones MI, Greenfield S, et al. Telemonitoring and self-management in the control of hypertension (TASMINH2): a randomised controlled trial. Lancet. 2010:376(9736):163-72.

10. Chobanian AV, Bakris GL, Black HR, Cushman WC, Green LA, Izzo JL Jr, et al. The seventh report of the joint national committee on prevention, detection, evaluation, and treatment of high blood pressure: the JNC 7 report. JAMA. 2003;289(19):2560-71.

11. Whelton PK, Carey RM, Aronow WS, Casey DE, Collins KJ, Himmelfarb CD, et al. ACC/AHA/AAPA/ABC/ACPM/AGS/APhA/ASH/ASPC/NMA/PCNA guideline for the prevention, detection, evaluation, and management of high blood pressure in adults: a report of the American College of Cardiology/American Heart Association Task Force on Clinical Practice Guidelines. J Am Coll Cardiol. 2017;2017:24430.

12. Leung AA, Daskalopoulou SS, Dasgupta K, McBrien K, Butalia S, Zarnke KB, et al. Hypertension Canada's 2017 guidelines for diagnosis, risk assessment, prevention, and treatment of hypertension in adults. Can J Cardiol. 2017;33(5):557-76.
13. Mancia G, Fagard R, Narkiewicz K, Redon J, Zanchetti A, Böhm M, et al. 2013 ESH/ESC Guidelines for the management of arterial hypertension: the Task Force for the management of arterial hypertension of the European Society of Hypertension (ESH) and of the European Society of Cardiology (ESC). Blood Press. 2013;22(4):193-278.

14. World Health Organization (WHO). A global brief on hypertension: silent killer, global public health crisis: World Health Day 2013. Geneva: World Health Organization; 2013.

15. Campbell NR, Lackland DT, Niebylski ML. High blood pressure: why prevention and control are urgent and important-a 2014 fact sheet from the World Hypertension League and the International Society of Hypertension. J Clin Hypertens. 2014;16(8):551-3.

16. Han H-R, Lee H, Commodore-Mensah Y, Kim M. Development and validation of the hypertension self-care profile: a practical tool to measure hypertension self-care. J CardiovasC Nurs. 2014;29(3):E11.

17. Dasgupta A, Sembiah S, Paul B, Ghosh A, Biswas B, Mallick N. Assessment of self-care practices among hypertensive patients: a clinic based study in rural area of Singur, West Bengal. Int J Community Med Public Health. 2017:5(1):262-7.

18. Shameena A, Badiger S. Retracted: medication adherence and health belief model among hypertensive patients attending rural health centres of a tertiary care hospital in South India. Int J Community Med Public Health. 2017;4(4):1159-65.

19. Iloh GUP, Amadi AN, Okafor GOC, Ikwudinma AO, Odu FU, Godswill-Uko EU. Adherence to lifestyle modifications among adult hypertensive nigerians with essential hypertension in a primary care clinic of a tertiary hospital in resource-poor environment of Eastern Nigeria. J Adv Med Med Res. 2014;4:3478-90.

20. Tibebu A, Mengistu D, Negesa L. Adherence to recommended lifestyle modifications and factors associated for hypertensive patients attending chronic follow-up units of selected public hospitals in Addis Ababa, Ethiopia. Patient Preference Adherence. 2017;11:323.

21. Buda ES, Hanfore LK, Fite RO, Buda AS. Lifestyle modification practice and associated factors among diagnosed hypertensive patients in selected hospitals, South Ethiopia. Clin Hypertens. 2017;23(1):26.

22. World Health Organization (WHO). Global action plan for the prevention and control of noncommunicable diseases 2013-2020. Geneva: World Health Organization; 2013.

23. Mekelle Univesity. Ayder comprehensive specialized hospital Mekelle. http://www.mu.edu.et/chs/index.php/ayder-referral-hospital. Accessed 2 Jan 2018.

24. Warren-Findlow J, Seymour RB. Prevalence rates of hypertension self-care activities among African Americans. J Natl Med Assoc. 2011;103(6):503-12.

25. Bilal M, Haseeb A, Lashkerwala SS, Zahid I, Siddiq K, Saad M, et al. Knowledge, awareness and self-care practices of hypertension among cardiac hypertensive patients. Glob J Heal Sci. 2016;8(2):9.

26. Heymann AD, Gross R, Tabenkin H, Porter B, Porath A. Factors associated with hypertensive patients' compliance with recommended lifestyle behaviors. IMAJ Israel Med Assoc J. 2011;13(9):553.

27. Schapira MM, Fletcher KE, Hayes A, Eastwood D, Patterson L, Ertl K, et al. The development and validation of the hypertension evaluation of lifestyle and management knowledge scale. J Clin Hypertens. 2012;14(7):461-6.

\section{Publisher's Note}

Springer Nature remains neutral with regard to jurisdictional claims in published maps and institutional affiliations. 